\title{
Application of Carbon Fibers to Construction Materials in Japan-A Review
}

\author{
Kensuke Okuda \\ Okuda Giken; 640-6 Kitano, Tokorozawa, 359 Japan
}

(Received February 28, 1992)

\begin{abstract}
Concrete-based materials reinforced with carbon fibers have been extensively used in the construction industry in Japan. The existing conditions of the application of them are reviewed.
\end{abstract}

KEYWORDS: Carbon fiber, Hydraulic cement, Concrete, Composite, CFRC (Carbon fiber reinforced concrete), Construction material

\section{Introduction}

After success in the 37-story ARK Mori Building which was completed in $1986^{1)}$, the application of carbon fibers to construction materials has progressed steadily, though it took more than fifteen years to practical use since basic studies had been done ${ }^{2), 3)}$.

The usage of carbon fibers as an reinforcing material to concretes is classified into two categories. One is reinforcements for fiber reinforced concretes, which have been applied to many practical structures including ARK Mori Building mentioned above. The other is for structural materials, in other words, the replacement of conventional iron rods and steel tendons, and is still now under development.

In this paper, reinforcing methods, characteristic features, reinforcing effects and typical examples of the applications in Japan are briefly reported.

\section{Reinforcing methods}

Hydraulic cements are weak under tension and against impact, though they have the advantages of high compressive strength, excellent workability, cheap price and so on. Such weakness of cements can be improved by fortifying them with suitable reinforcements, such as iron rods, prestressed concrete steel and fibrous materials.
Carbon fibers are superior reinforcing materials to concretes as shown later. The reinforcing methods of carbon fibers are essentially the same as those of conventional materials.

As indicated in Table 1, one of the reinforcing methods is for improving the properties of concretes themselves, where short fiber-based intermediate materials are mainly used as reinforcements to non or secondary structural materials. The randomly dispersed short fiber system is so-called carbon fiber reinforced concretes (CFRC) in a narrow sense. The second group is the application to structural construction materials for which reinforcements are various forms of polymer matrix composites, e.g. rods, cables, 3D woven fabrics and so on.

We will summarize the state of the art of both methods.

\section{Fiber Reinforced Concretes}

The characteristic features of carbon fibers as reinforcing materials for concretes compared with other reinforcing fibers are as follows:

- Excellent alkali resistance (which makes possible autoclaving)

- Higher tensile strength and tensile modulus of elasticity

- Light weight 
Table 1 Reinforcing methods to concretes and form of carbon fiber-based reinforcing materials.

\begin{tabular}{l|l}
\hline $\begin{array}{l}\text { Reinforcement for } \\
\text { fiber reinforced } \\
\text { concrete }\end{array}$ & $\begin{array}{l}\text { Randomly dispersed short fiber } \\
\text { system (chopped fiber, chopped } \\
\text { strand) } \\
\text { Reinforcing with woven fabric } \\
\text { (mesh cloth) or non-woven } \\
\text { fabric (mat) }\end{array}$ \\
\hline $\begin{array}{l}\text { Reinforcement for } \\
\text { structural materials }\end{array}$ & $\begin{array}{l}\text { Strand-based reinforcement } \\
\text { Polymer matrix composite rod/wire } \\
\text { Polymer matrix composite cable } \\
\text { Polymer matrix composite grid re- } \\
\text { inforcement (2D, 3D) } \\
\text { Woven fabric-based composite re- } \\
\text { inforcement (2D, 3D) }\end{array}$ \\
\hline
\end{tabular}

- High heat resistance

- High wear resistance

- Electrically and thermally conductive

- Superior stability to biodegradation

The type and degree of reinforcing effects depend on the grade of fibers, the form of reinforcements, the formulation of composites, the fabrication method, and so forth. In the case of the short fiber dispersed system, which is used on a large scale, the following significant reinforcing effects have been confirmed by many researchers:

- Remarkable improvement in tensile strength and flexural strength (increase of strength by several times to some ten times)

- Higher toughness and ductility (increase of bending toughness by several times to more than fifty times)

- Significant improvement against impact force

- Protection to crack formation due to drying shrinkage

- Excellent durability

- Good wear resistance

- Dimensional stability

- Antistatic-charge

- Light weight

These reinforcing effects yield many advantages for actual construction. An example is the CFRC curtain wall which is applied to ARK Mori Building4). The CFRC curtain wall is as light as two fifth of the conventional precast concrete curtain wall with the same performance, because of the low density and high mechanical property of CFRC. Moreover, the high dimensional stability which results from autoclave-
Conventional precast concrete curtain wall

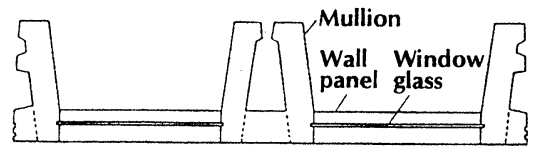

CFRC curtain wall

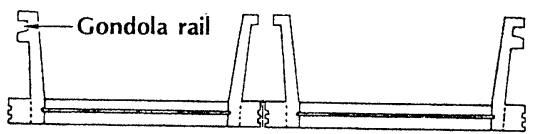

Fig. 1 Cross sections of conventional curtain wall (above) and CF RC one for ARK Mori Building (below) (mass: 5 tons and 2 tons respectively; mass of unit of CFRC: 1 ton).

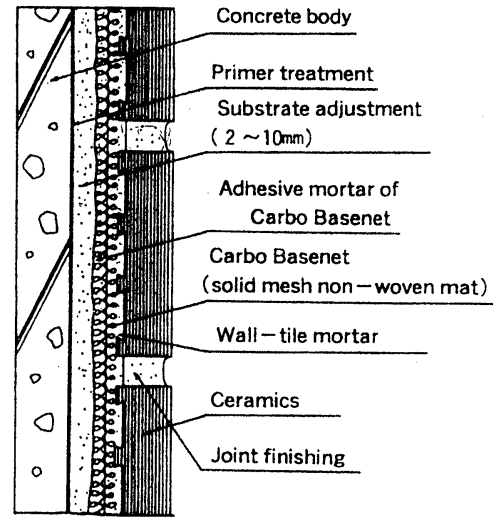

Fig. 2 A schematic representation of the basenet engineering method for preventing fallingdown of tiling from the concrete structure.

curing makes it possible to reduce the size of the unit of the CFRC curtain wall to half, in other words, the mass of the unit is one fifth of that of the conventional one (see Fig. 1).

Another is a new engineering method for preventing falling-down of tiling from concrete structures ${ }^{5)}$. The falling-down of tiling, which is an important issue in the construction industry, is due mainly to fatigue failure of adherent mortar layer. The fatigue failure originates in the stress caused by repeating differential movement among exterior tiles, mortar layer and concrete structures.

The characteristic reinforcing effects are to reduce the generating stress and to increase adhesive force between the members, by fortifying the adherent mortar with basenets-non-woven fabrics of carbon fibers as shown in Fig. 2. Consequently prevention of the falling- 
down can be achieved to a certain degree as a practical advantage. An additional advantage of carbon fibers for this method is excellent fire resistance as compared with organic fibers.

\section{Structural Materials}

A demand for light weight/corrosion resistant construction materials has increased with the progress of construction technology and the yearly diversification of construction space. Consequently various types of polymer matrix composites fortified with high performance fibers including carbon fibers have been actively developed for replacing conventional steelbased reinforcements which have some weak points such as low corrosion resistance to the briny environment, high density, in spite of their long history of near 150 years.

The carbon fiber-based composite (CFRP) reinforcements have many advantages as compared with the other fiber systems, and the characteristic features of them are as follows:

- Superior stability to salt damage

- Excellent alkali resistance

- Light weight (compared with steel)

- High tensile strength and tensile modulus of elasticity

- Low relaxation

- High fatigue resistance

- High creep resistance

- Non magnetism (compared with steel)

- Electrically conductive (compared with other new fibers)

The CFRP reinforcements have some weak points such as low toughness, low ductility, low thermal expansion, low adhesion to concretes and high price. For example, the coefficient of thermal expansion of CFRP reinforcements does not exceed $0.5 \times 10^{-5} \mathrm{~K}^{-1}$, while those of concretes and steel rods are $1.0 \sim 1.4 \times$ $10^{-5} \mathrm{~K}^{-1}$ and $1.0 \sim 1.1 \times 10^{-5} \mathrm{~K}^{-1}$, respectively.

In response to variety in practical use of advanced reinforcements, improvement in performance of the reinforcements, increase in adhesion force to concretes and development of various material forms have been done. Concerning the product forms, complex shaped reinforcing materials including multi-axial plane grids and 3-dimensional (3D) structures have been developed. Typical product forms of the carbon fiber-based rein-

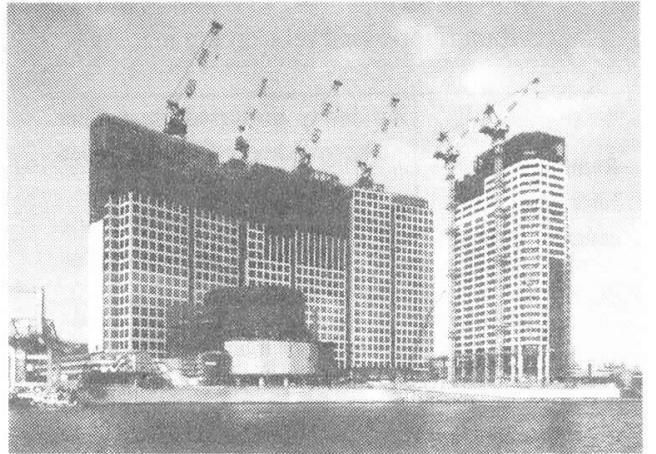

Fig. 3 An overall view of Sea Fort Square where 3D woven fabric-based curtain walls are applied (By courtesy of Mr. H. Nakagawa of Kajima Corporation).

forcements on the market are summarized in Table 1. The matrix materials of the products are mostly epoxy resin and vinyl ester resin at present.

To take 3D carbon fiber woven fabric-based reinforcements which were applied to the curtain walls for Sea Fort Square ${ }^{6)}$ (Fig. 3), the 3D reinforcements show a suppression effect against crack propagation in addition to excellent reinforcing effects on mechanical properties of the concrete panels fortified with them. The flexural strength of the concrete panels is three to four times higher than that of the RC panels fortified with treble the quantity of the tensile component of the reinforcements. Moreover, the flexural properties, particularly decreasing in the stress after cracked, can be improved by adding the short fibers to matrix concretes.

In the case of the application to tension members for prestressed concretes, fixing devices of the ends (anchors) are indispensable. Various fixing methods suitable to the composite reinforcements have been developed extensively ${ }^{7,8)}$.

\section{Application}

Typical examples of the constructions where carbon fibers were applied are listed in Table 2 .

The light weight CFRC has been used in many structures including skyscrapers as mainly vertical members such as curtain walls for about ten years. Moreover, short fibers were also applied to conductive concretes for reducing ground resistance of power transmission towers etc., anti-corrosion flooring and so 
Table 2 Typical examples of the application of carbon fibers to the construction-members where carbon fibers are used and typical constructions to which the members are applied.

\begin{tabular}{l|l|l}
\hline \multicolumn{1}{c|}{ Material } & \multicolumn{1}{|c}{ Member } & \multicolumn{1}{c}{ Typical construction } \\
\hline Short fiber & $\begin{array}{l}\text { Tile panel } \\
\text { Curtain wall } \\
\text { Tiled wall } \\
\text { Decorative form } \\
\text { Free access floor } \\
\text { Window ledge } \\
\text { Interior wall } \\
\text { Conductive concrete } \\
\text { Dry mortar } \\
\text { Anti-corrosion } \\
\text { flooring }\end{array}$ & $\begin{array}{l}\text { Domes of Al Shaheed Monument in Baghdad (40m in height, 45m in diameter) } \\
\text { ARK Mori Building (37-story), Suidobashi Building of Tokyo Dental College } \\
\text { (granite tile placing) } \\
\text { Odori Station (Sapporo Civic Subway) } \\
\text { Kajima Corp. Head Office Building } \\
\text { Ohte Center Building }\end{array}$ \\
\hline Non-woven fabric & Tiling work & $\begin{array}{l}\text { Power plants, power transmission towers (for reducing ground resistance) } \\
\text { (resin mortar) }\end{array}$ \\
\hline Strand & $\begin{array}{l}\text { Smokestack } \\
\text { Concrete structure }\end{array}$ & $\begin{array}{l}\text { (aseismatic reinforcing) } \\
\text { (reparing works for beam, slab, column etc.) }\end{array}$ \\
\hline Rod $^{2)}$ & Beam & $\begin{array}{l}\text { Main gate of Tokyo-Kita Golf Club (prestressed concrete structure by the } \\
\text { post-tensioning method) }\end{array}$ \\
\hline Cable $^{2)}$ & Beam & Shingu Bridge (pre-tension type PC slub bridge) \\
\hline 3D woven fabric ${ }^{2)}$ & Curtain wall & Sea Fort Square (column beam type curtain wall) \\
\hline
\end{tabular}

1) Resin impregnated, 2) Polymer matrix composite.

on.

On the other hand, the application of the reinforcements for structural materials lags behind that of CFRC, but has been progressing steadily and slowly, in spite of the fireproof regulations, which restrict the application to some limited parts presently.

The utilization in civil engineering fields precedes the application to architectures, because of mild regulations in the former. For example, in 1988, the polymer matrix composite cables were applied to the tension members of Shingu Bridge ${ }^{8)}$-a PC slab bridge by pretension methods, in place of steel wire, because the bridge is located in a prominent salt damage area in Japan.

\section{Conclusion}

Carbon fibers and their polymer matrix composites are superior reinforcements to concretes, although there is a competition with other fibers. CFRC has been widely used in Japan. This fact suggests that the application technology of short fiber systems is practically established. The CFRP-based reinforcing materials are still under development. It is necessary to develop new design concept and advanced methods of construction and to modify the construction regulations, for wide usage of them.

\section{Acknowledgment}

The author expresses his thanks to $\mathrm{Mr}$. $\mathrm{H}$. Nakagawa of Kajima Corporation for presenting the photograph of Sea Fort Square.

\section{References}

1) S. Akihama, Kenchiku-Gijutsu 1985.12 (No. 412) 139 148.

2) M.A. Ali, A.J. Majumdar and D.L. Rayment, Cement \& Concrete Res. 2, 201 212 (1972).

3) Kureha Chem. Ind. Co., Ltd., Unpublished works.

4) Kajima Corp., Technical Data Series No. 88-40E.

5) Y. Hayashi, Kenchiku-Shiage-Gijutsu 1991.10, 4 50.

6) M. Kobayashi, T. Suenage, T. Ohuchi, S. Watanabe and H. Nakagawa, Rep. of Kajima Inst. of Constr. Tech. 1991, 24 25.

7) T. Katou, N. Hayashida, T. Kobori and K. Ouzeki, Tech. Rep. of Kumagai Gumi Co., Ltd. No. 49/1991.3, 95 102.

8) Tokyo Rope Manufac. Co., Ltd., Technical Information. 